\title{
Growth of ZnO Nanorod Arrays on Flexible Substrates: Effect of Precursor Solution Concentration
}

\author{
Fei Tong, ${ }^{1}$ Kyusang Kim, ${ }^{1}$ Yaqi Wang, ${ }^{1}$ Resham Thapa, ${ }^{1}$ Yogesh Sharma, ${ }^{1}$ Aaron Modic, ${ }^{1}$ \\ Ayayi Claude Ahyi, ${ }^{1}$ Tamara Issacs-Smith, ${ }^{1}$ John Williams, ${ }^{1}$ Hosang Ahn, ${ }^{2}$ Hyejin Park, ${ }^{2}$ \\ Dong-Joo Kim, ${ }^{2}$ Sungkoo Lee, ${ }^{3}$ Eunhee Lim, ${ }^{3}$ Kyeong K. Lee, ${ }^{3}$ and Minseo Park ${ }^{1}$ \\ ${ }^{1}$ Physics Department, Auburn University, Auburn, AL 36849, USA \\ ${ }^{2}$ Materials Research and Education Center, Department of Mechanical Engineering, Auburn University, Auburn, AL 36849, USA \\ ${ }^{3}$ Department of Eco and Functional Materials, Korea Institute of Industrial Technology, Cheonan, \\ Choongnam 331-825, Republic of Korea
}

Correspondence should be addressed to Minseo Park, park@physics.auburn.edu

Received 7 May 2012; Accepted 11 June 2012

Academic Editors: A. Bendavid, P. Kumbhakar, A. Portavoce, A. Sorrentino, and C. Wang

Copyright ( 2012 Fei Tong et al. This is an open access article distributed under the Creative Commons Attribution License, which permits unrestricted use, distribution, and reproduction in any medium, provided the original work is properly cited.

We report a low-temperature aqueous solution growth of uniformly aligned $\mathrm{ZnO}$ nanorod arrays on flexible substrates. The substrate is Indium Tin Oxide (ITO) film coated on polyethylene terephthalate (PET). Solutions with five different concentrations of the precursors with equimolar Zinc Nitrate and Hexamethylenetetramine (HMT) in distilled water were prepared to systematically study the effect of precursor solution concentration on the structural and optical properties of $\mathrm{ZnO}$ nanorods. It was concluded that the precursor concentration have great influence on the morphology, crystal quality, and optical property of ZnO nanorods. The diameter, density, and orientation of the nanorods are dependent on the precursor solution concentration. X-ray diffraction and micro-Raman spectroscopy showed that the $\mathrm{ZnO}$ nanorods with the highest concentration of $50 \mathrm{mM}$ were highly aligned and have the highest level of surface coverage. It was also found that the diameter and length of the nanorods increases upon increasing precursor solution concentration. This is the first systematic investigation of studying the effect of precursor solution concentration on the quality of $\mathrm{ZnO}$ nanorods grown on ITO/PET substrates by low-temperature solution method. We believe that our work will contribute to the realization of flexible organic-inorganic hybrid solar cell based on $\mathrm{ZnO}$ nanorods and conjugated polymer.

\section{Introduction}

Zinc oxide $(\mathrm{ZnO})$ is a semiconductor with a wide direct band gap of $3.37 \mathrm{eV}$ and a large exciton binding energy of $60 \mathrm{meV}$, which makes the material useful for optoelectronic application $[1,2]$. Nanostructures of $\mathrm{ZnO}$ such as $\mathrm{ZnO}$ nanorods and nanowires have received increased attention due to their excellent electrical and optical properties [3]. Due to the high surface-to-volume ratio provided by the one-dimensional (1D) nanostructure, $\mathrm{ZnO}$ nanorod arrays are considered suitable to the application for hybrid photovoltaic devices [4-7]. In the past few years, $\mathrm{ZnO}$ nanorods have been synthesized via various physical and chemical methods including vapor phase synthesis [8-10], metalorganic chemical vapor deposition (MOCVD) [11-13], and solution-based synthesis
[14-17]. Among these routes, solution-based method has the advantages of simplicity, low costs, low growth temperature, and easy coating of large surfaces Intensive research has been focused on the solution growth process of $\mathrm{ZnO}$ nanorods on ITO-coated glass substrates. Guo et al. [18] have systematically studied the effect of processing conditions such as pretreatment of the substrates, growth temperature, deposition time, and the concentration of the precursors on the morphology and alignment ordering of $\mathrm{ZnO}$ nanorod arrays during solution process.

Aiming at overcoming the problems endemic to organic solar cells, researchers worldwide have turned their attention to organic/inorganic hybrid solar cells. An example of such a hybrid solar cell is the one with $\mathrm{ZnO}$ nanorod arrays coated on ITO-coated glass substrates and they found that nanorods 
play an important role in improving electron transport speed [4-7]. In addition, it will be an innovation to build plastic hybrid solar cells [19] consisting of $\mathrm{ZnO}$ nanorods and conjugated polymer on ITO/PET substrates since plastic materials are cheap, lightweight, bendable, and suitable to large-scale roll-to-roll manufacturing. To synthesize $\mathrm{ZnO}$ nanorods on plastic substrate, low-temperature solutionbased process is highly suitable. Recently, Kim et al. [20] have reported the fabrication of flexible dye-sensitized solar cells by synthesizing $\mathrm{ZnO}$ NRs on ITO-coated PET substrates. Hu et al. [21] have studied density, adhesion, and electrochromic performance of $\mathrm{ZnO}$ nanorod arrays on the ITO-coated flexible substrates. However, the growth conditions such as growth temperature, concentration of the precursor, time duration concerning the solution growth of $\mathrm{ZnO}$ nanorods on ITO-coated PET substrates have not been systematically investigated.

In this investigation, we have synthesized $\mathrm{ZnO}$ nanorods on flexible ITO substrates by a solution-based approach under different precursor solution concentrations while time duration and temperature were fixed at $2 \mathrm{~h}$ and $85^{\circ} \mathrm{C}$, respectively. The aqueous solution contains equimolar of zinc nitrate and hexamethylenetetramine (HMT), which are the main chemicals used by many research groups $[16,17,22]$ in solution growth of $\mathrm{ZnO}$ nanorods. One of the major merits of this aqueous solution method is the use of distilled water instead of using alcohol as the solvent, since water is more inexpensive and environmentally friendly [23]. The influence of the precursor solution concentration on the growth of the $\mathrm{ZnO}$ nanorods on ITO-coated PET substrates was systematically investigated for the first time. We have demonstrated that the morphology, crystalline, and optical property of $\mathrm{ZnO}$ nanorods on ITO-coated PET substrates can be controlled by adjusting the concentration of the aqueous chemical solution.

\section{Experiment}

Flexible-indium-tin-oxide (ITO)-coated PET substrates were purchased from Delta Technologies. The substrates have a multi-layered films composed of $\operatorname{In}_{2} \mathrm{O}_{3} / \mathrm{Au} / \mathrm{Ag}$ sputtered on an optical grade polyethylene terephthalate (PET) film $(0.2 \mathrm{~mm})$. The sheet resistance of the coated ITO is 4 $10 \Omega$ square $^{-1}$. The substrates were cut into 1 inch $\times 1$ inch pieces. Prior to the growth of the $\mathrm{ZnO}$ nanorods, the ITOcoated PET substrates were cleaned sequentially by ultrasonic agitation in a detergent solution, acetone, isopropanol alcohol, and distilled water for $5 \mathrm{~min}$, followed by nitrogen blow drying.

The zinc oxide nanorods were prepared by a two-step process which was similar to the procedure reported in the literature $[17,18]$. In the first step, $\mathrm{ZnO}$ seed layer with an approximate thickness of $40 \mathrm{~nm}$ were radio-frequency (RF) sputtered on the flexible ITO substrates. In the second step, an aqueous solution which contains zinc nitrate hexahydrate $\left(\mathrm{Zn}\left(\mathrm{NO}_{3}\right)_{2} \cdot 6 \mathrm{H}_{2} \mathrm{O}\right.$, Crystalline/Certified, Fisher Chemical, F.W. $=297.49)$, and the same mole of hexamethylenetetramine (HMT, Sigma-Aldrich, M.W. $=140.19$ ) in $400 \mathrm{~mL}$
TABLE 1: The average diameter, length, and aspect ratio (length/ diameter) of $\mathrm{ZnO}$ nanorods on flexible ITO/PET substrates under different solution concentrations.

\begin{tabular}{lccccc}
\hline Solution con. (mM/L) & 50 & 37.5 & 25 & 18.75 & 12.5 \\
Average diameter (nm) & 397.4 & 265.8 & 251.1 & 225 & 173.6 \\
Average length (nm) & 1200 & 950 & 830 & 750 & 600 \\
Aspect ratio (Len./Dia.) & 3.02 & 3.57 & 3.31 & 3.33 & 3.46 \\
\hline
\end{tabular}

distilled water mixture was prepared in a beaker and was stirred for $10 \mathrm{~min}$ at room temperature. Subsequently, asprepared substrates were immersed into the aqueous solution which was then transferred to an isothermal hot water bath (IsoTemp 202 Water Bath, Fisher Scientific). The solution synthesis process of $\mathrm{ZnO}$ nanorods was conducted at $85^{\circ} \mathrm{C}$ for 2 hours. The temperature of the water was elevated to $85^{\circ} \mathrm{C}$ before dipping the aqueous solution into the hot water bath. After 2 hours of solution growth, the substrates were rinsed with distilled water for several times and then dried in air at room temperature.

Five different concentrations $(50 \mathrm{mM}, 37.5 \mathrm{mM}, 25 \mathrm{mM}$, $18.75 \mathrm{mM}$, and $12.5 \mathrm{mM}$ ) solutions of the Zinc Nitrate Hexahydrate and HMT in distilled water were prepared. The asprepared ITO/PET substrates with the dense $\mathrm{ZnO}$ seed layers were suspended horizontally upside-down in a beaker which contains the aqueous solution of equimolar of Zinc Nitrate Hexahydrate and HMT. The ITO side of the sample was facing down and the distance between the sample and the bottom of the beaker is about $1 \mathrm{~cm}$.

As-grown $\mathrm{ZnO}$ nanorods were studied using scanning electron microscopy (SEM), X-ray diffraction (XRD), microRaman spectroscopy, and photoluminescence spectroscopy. Field emission-scanning microscope (FE-SEM, JEOL JSM$7000 \mathrm{~F}$ ) was used to observe the morphology of the $\mathrm{ZnO}$ nanorods on ITO flexible substrates. Bruker D8 X-ray Diffractometer was used to characterize the crystalline quality of the $\mathrm{ZnO}$ nanorods on ITO-coated PET substrates. Room temperature PL spectra were collected using the $325 \mathrm{~nm}$ line $(20 \mathrm{~mW})$ from a continuous-wave $\mathrm{He}-\mathrm{Cd}$ laser (Kimmon Electric). Room temperature Micro-Raman spectroscopy was conducted using the $441.563 \mathrm{~nm}$ line $(80 \mathrm{~mW})$ from HeCd laser. Back-scattering geometry was employed for microRaman scattering experiment, and the polarization state of the scattered light was not analyzed.

\section{Results and Discussion}

After the growth of the $\mathrm{ZnO}$ nanorods, scanning electron microscopy was used to study the morphology of the $\mathrm{ZnO}$ nanorod arrays. Figure 1 shows the SEM images of $\mathrm{ZnO}$ nanorods grown with five different solution concentrations, respectively. As shown in the figure, arrays of $\mathrm{ZnO}$ nanorods with hexagonal shapes were successfully formed under various solution concentrations. Based on the SEM images, average values of the length, diameter, and aspect ratio of the nanorods are summarized in Table 1 and are plotted in Figure 2 as a function of solution concentration. It was found 


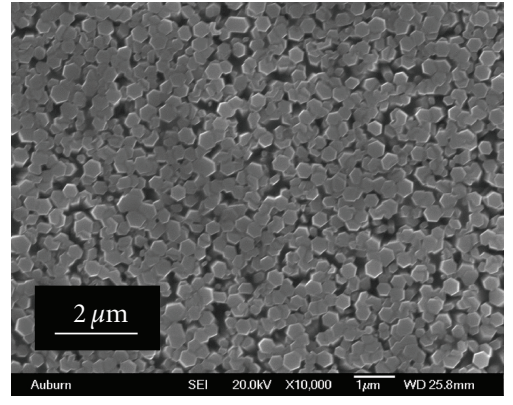

(a)

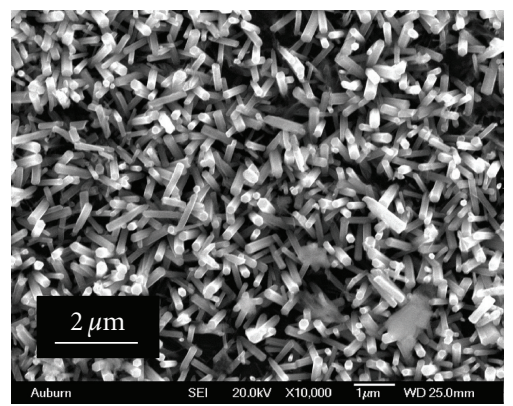

(d)

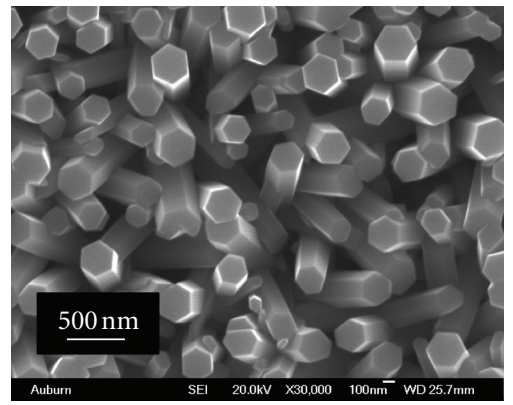

(g)

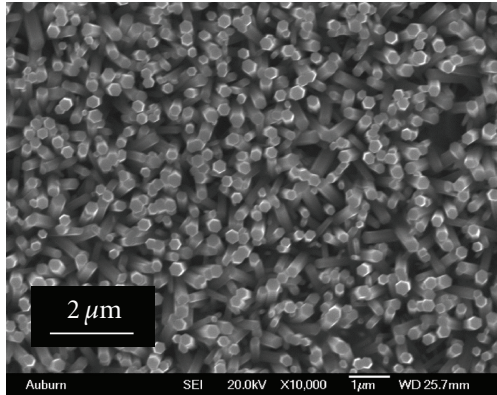

(b)

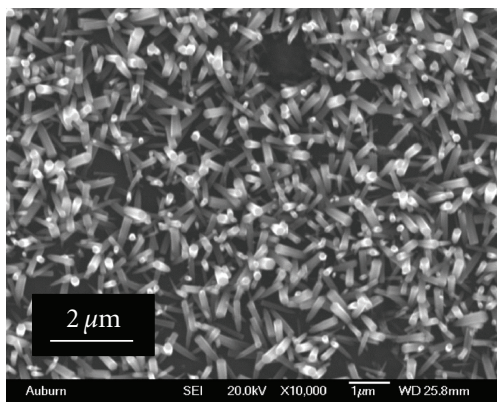

(e)

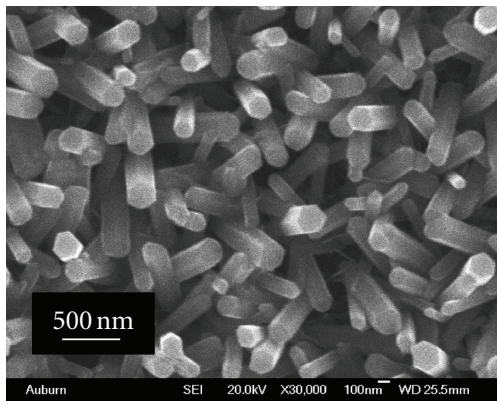

(h)

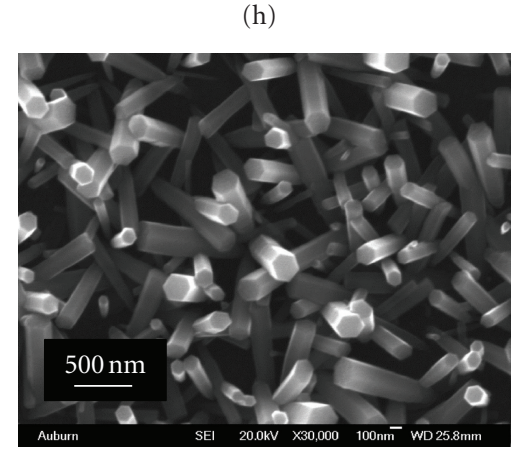

(j)

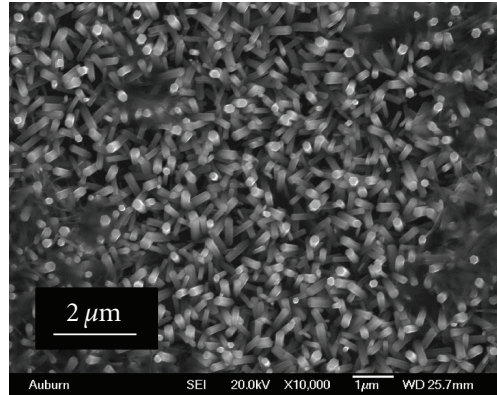

(c)

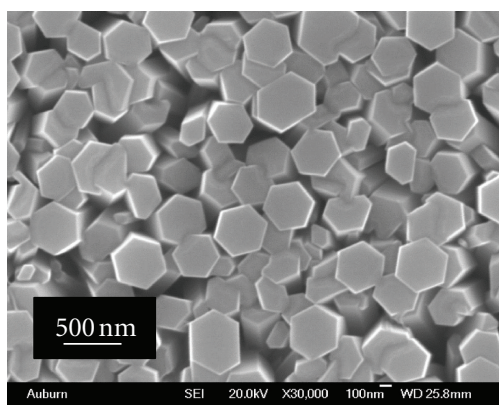

(f)

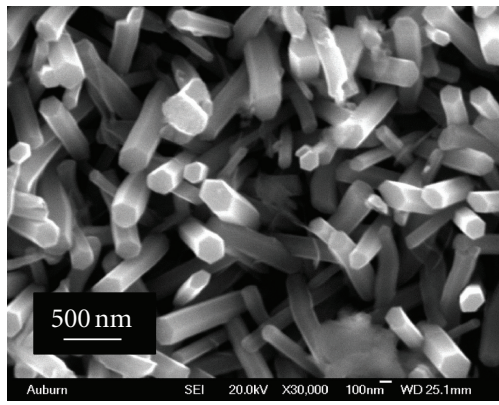

(i)

FIGURE 1: SEM images of ZnO nanorods synthesized on ITO/PET substrates under different solution concentrations: under lower magnification (scale bar $-2 \mu \mathrm{m}$ ): (a) $50 \mathrm{mM}$, (b) $37.5 \mathrm{mM}$, (c) $25 \mathrm{mM}$, (d) $18.75 \mathrm{mM}$, and (e) $12.5 \mathrm{mM}$ : under higher magnification (scale bar $-500 \mathrm{~nm}$ ); (f) $50 \mathrm{mM}$, (g) $37.5 \mathrm{mM}$, (h) $25 \mathrm{mM}$, (i) $18.75 \mathrm{mM}$, and (j) $12.5 \mathrm{mM}$.

that the diameter and length of the $\mathrm{ZnO}$ nanorod increases as the precursor solution concentration increases. The average diameter and length of the nanorod increased almost lineally from about $174 \mathrm{~nm}$ to $397 \mathrm{~nm}$ and from $600 \mathrm{~nm}$ to $1200 \mathrm{~nm}$, respectively, upon increase of the solution concentration from $12.5 \mathrm{mM}$ to $50 \mathrm{mM}$. It was found that the diameter, length, and density of the $\mathrm{ZnO}$ nanorods could be well controlled by changing the solution concentration during growth. It also appears that the coverage of the nanorod array on the substrate increases as the precursor solution concentration increases. In addition, the nanorods grown with higher concentration precursor solution exhibited higher degree of alignment than the nanorods with lower concentration ones. 


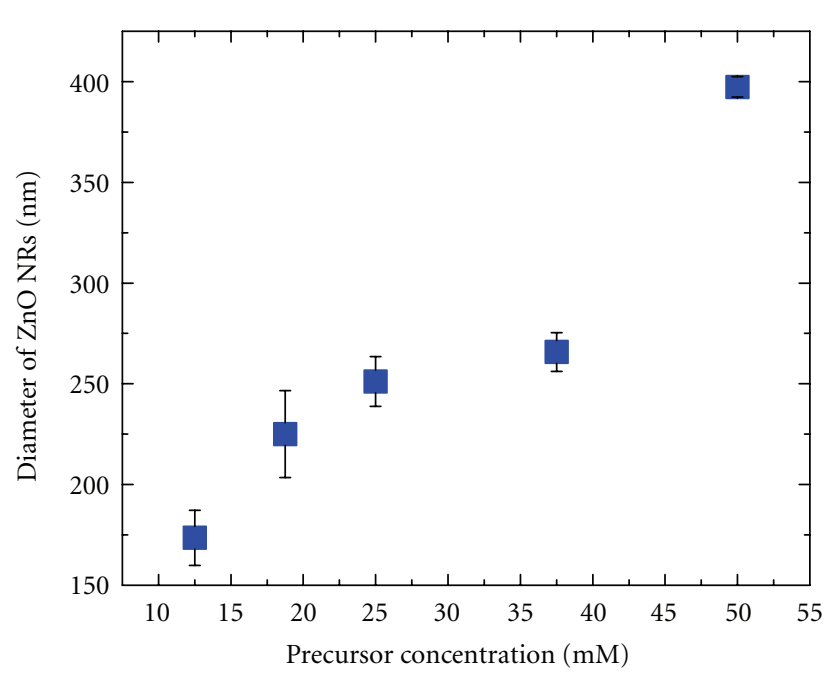

(a)

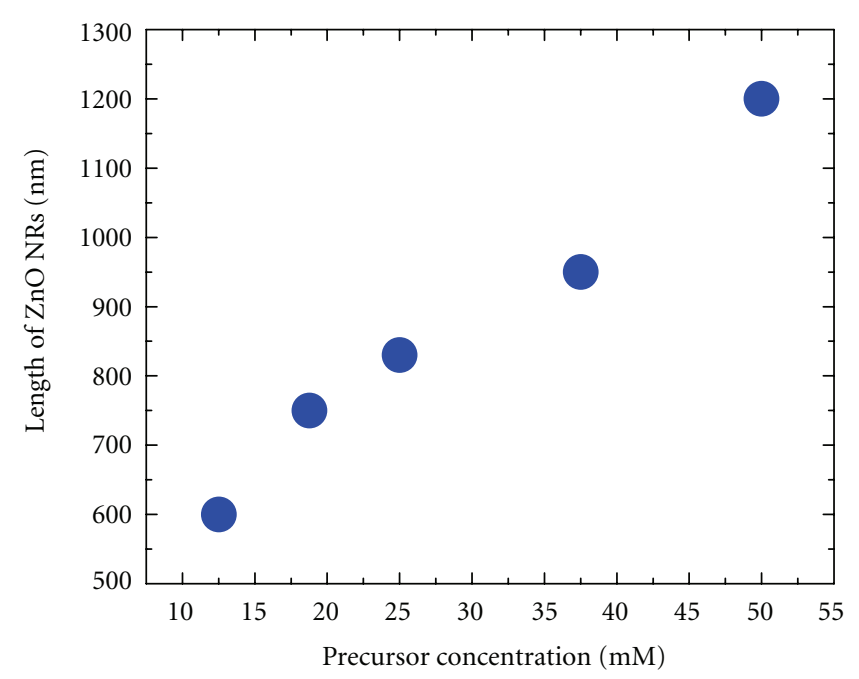

(b)

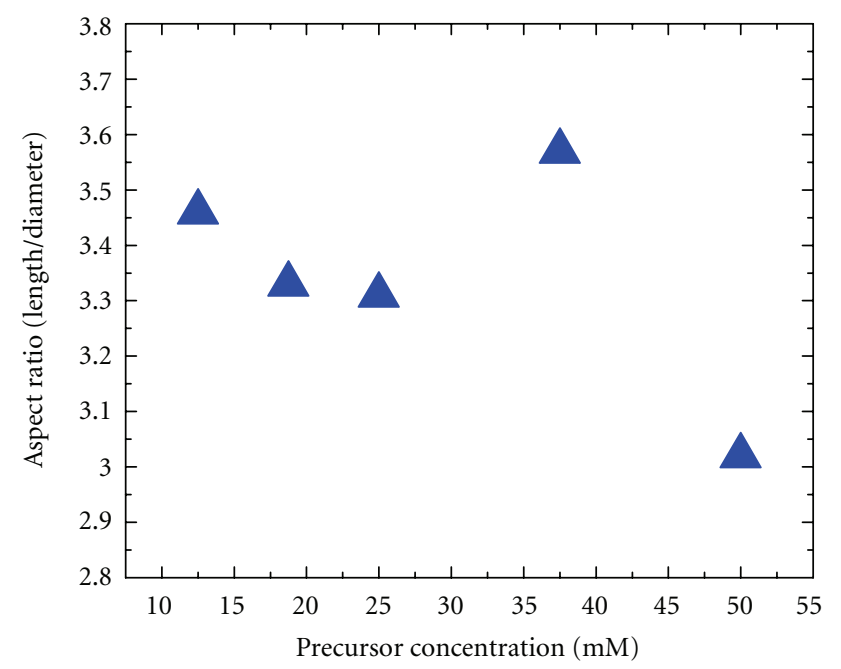

(c)

Figure 2: The plots of (a) average nanorod diameter, (b) average nanorod length, and (c) aspect ratio as a function of the solution concentration.

The XRD measurement was conducted to characterize the crystalline quality and orientation of the $\mathrm{ZnO}$ nanorods. Figure 3 shows the XRD patterns of $\mathrm{ZnO}$ nanorods grown under different solution concentrations on ITO/PET substrates. The XRD pattern of each sample was originated both from the $\mathrm{ZnO}$ nanorods and the ITO/PET substrates. The Xray diffraction result is in agreement with the standard diffraction pattern of hexagonal phase $\mathrm{ZnO}$ wurtzite structure from the Joint Committee on Powder Diffraction Standards (JCPDS 36-1451) [24]. The diffraction peaks corresponding to the lattice planes (100), (002), (101), (102), (110), and (103) are indexed. In the case of the sample with the concentration of $50 \mathrm{mM}$, the sharp and distinct diffraction peak at $2 \theta=34.41^{\circ}$ due to $\mathrm{ZnO}$ (002) crystal plane shows the strongest intensity, indicating its strong $c$ axis orientation, and the nanorods are preferentially oriented perpendicularly to the substrate. The notable difference in the full-width at half-maximum (FWHM) strongly supports our speculation that $\mathrm{ZnO}$ nanorod crystal promotes along the (001) direction [25]. It was observed that the relative intensity of the (002) diffraction peak with respect to other peaks decreases as the precursor concentration decreases, indicating that the orientation of the nanorods arrays becomes randomized. The XRD results are consistent to SEM data.

Photoluminescence measurement was employed to study the influence of precursor solution concentration on the optical property of the $\mathrm{ZnO}$ nanorods grown on ITO/PET substrates. Room temperature PL spectra from the $\mathrm{ZnO}$ nanorods grown under various precursor concentrations and from the bare ITO-coated PET substrate are shown in Figure 4 . The PL spectra from the $\mathrm{ZnO}$ nanorods typically exhibit two bands: a strong and sharp peak at about $385 \mathrm{~nm}$ $(3.22 \mathrm{eV}, \mathrm{UV}$ emission) and a broad band at around $530 \mathrm{~nm}$ ( $2.34 \mathrm{eV}$, visible emission). The former is a typical near band edge transition of intrinsic $\mathrm{ZnO}$ and is related to excitonic 


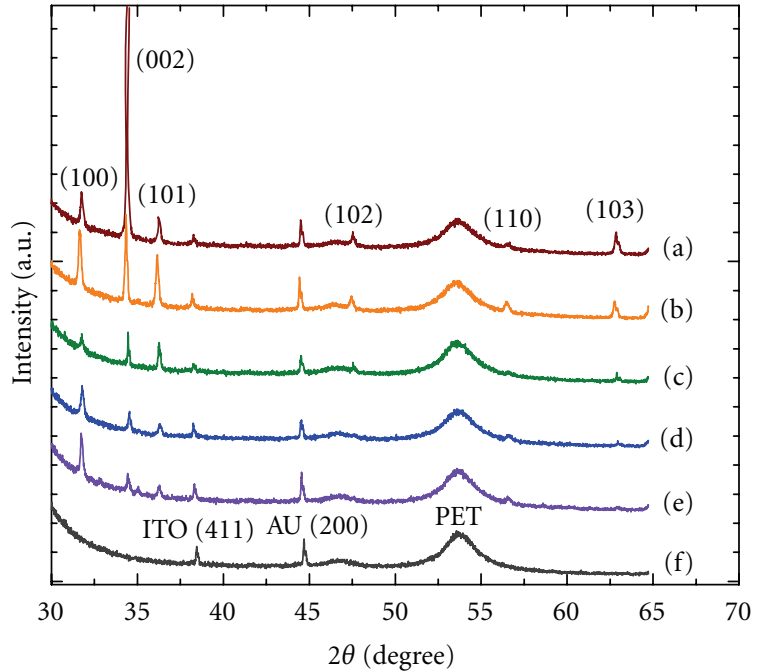

Figure 3: XRD patterns of $\mathrm{ZnO}$ nanorods grown on ITO/PET substrates under different solution concentrations: (a) $50 \mathrm{mM}$, (b) $37.5 \mathrm{mM}$, (c) $25 \mathrm{mM}$, (d) $18.75 \mathrm{mM}$, (e) $12.5 \mathrm{mM}$, and (f) bare ITO/ PET substrates.
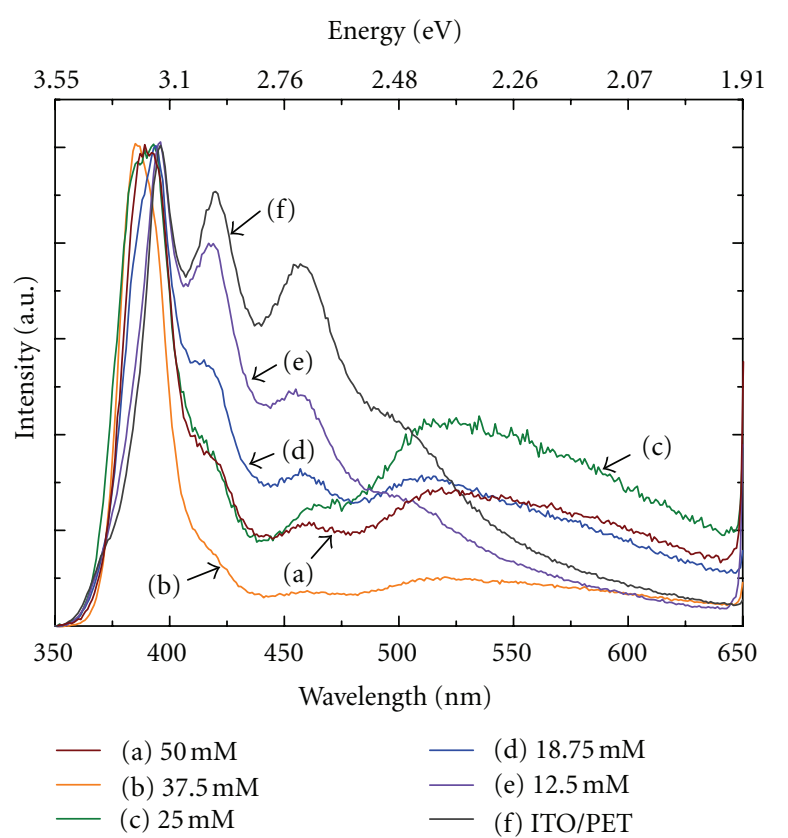

FIgURe 4: PL spectra of $\mathrm{ZnO}$ nanorods synthesized on ITO/PET substrates under different precursor concentrations: (a) $50 \mathrm{mM}$, (b) $37.5 \mathrm{mM}$, (c) $25 \mathrm{mM}$, (d) $18.75 \mathrm{mM}$, (e) $12.5 \mathrm{mM}$, and (f) bare ITO/ PET substrates.

process [26-28]. The latter visible band is considered to be resulted from the impurities and/or structural defects such as singly ionized oxygen vacancies in $\mathrm{ZnO}[29,30]$. The PL spectra of the $\mathrm{ZnO}$ nanorods grown from the solution with the lowest precursor concentration of $12.5 \mathrm{mM}$ were mainly dominated by peaks of the bare ITO/PET substrates, which indicate that the coverage of the $\mathrm{ZnO}$ nanorods on the ITO surface is substantially low. As can be seen from the PL

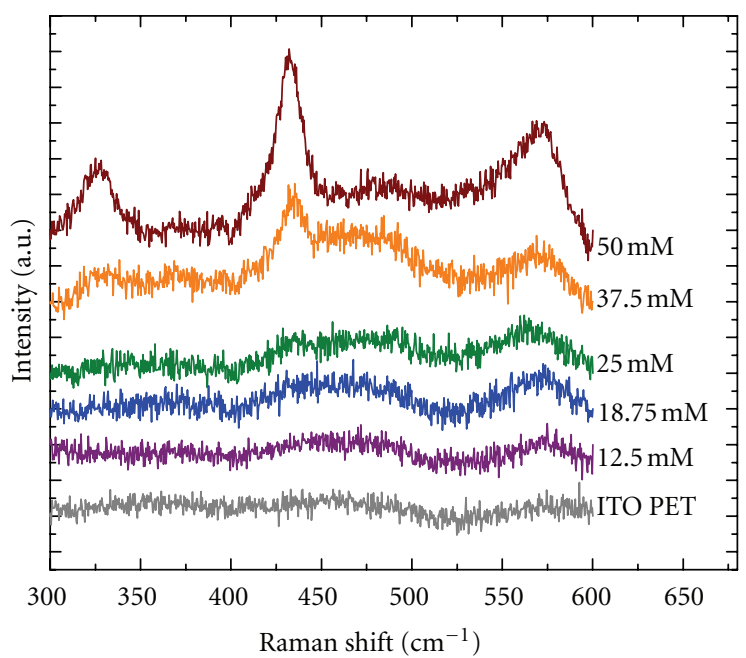

FIGURE 5: Raman scattering spectra of $\mathrm{ZnO}$ nanorods synthesized on ITO/PET substrates under different precursor concentrations: $50 \mathrm{mM}, 37.5 \mathrm{mM}, 25 \mathrm{mM}, 18.75 \mathrm{mM}, 12.5 \mathrm{mM}$ and bare ITO/PET substrates.

spectra, the contribution from the $\mathrm{ZnO}$ becomes dominant as the precursor solution concentration increases.

Micro-Raman spectroscopy was used to further analyze the quality of the $\mathrm{ZnO}$ nanorods. Wurtzite form of $\mathrm{ZnO}$ belongs to the space group $C_{6 v}^{4}$ with two formula units per primitive cell [31]. Group theory predicts the following optical modes at the $\Gamma$ point of the Brillouin zone: $A_{1}+E_{1}+$ $2 E_{2}+2 B_{1}$. Among these modes, $A_{1}, E_{1}$ and $2 E_{2}$ modes are Raman active, $2 B_{1}$ modes are silent, and $A_{1}$ and $E_{1}$ modes are infrared active. Both $A_{1}$ and $E_{1}$ modes split into transverse optical (TO) and longitudinal optical (LO) phonons [32]. Figure 5 shows the room temperature micro-Raman spectra (after baseline subtraction) collected from the five samples that were grown under different precursor concentrations and from the bare ITO/PET substrate. Lorentzian functions were employed to fit the Raman spectra in the region between 300 and $600 \mathrm{~cm}^{-1}$. The observed peaks at about 438 and $586 \mathrm{~cm}^{-1}$ are assigned to be $E_{2}^{(2)}$ (high-frequency $E_{2}$ mode) and Quasi-LO (QLO), respectively, [33-35]. The peak at $329 \mathrm{~cm}^{-1}$ results from the multiple phonon scattering processes [36]. As can be seen from Figure 5, the intensities of the $\mathrm{ZnO}$ Raman peak become higher as the precursor concentration increases, which indicate the increase in the crystal quality of the nanorods and/or the increase in the coverage of the nanorod arrays on the substrate. The Raman scattering result is in agreement with the X-ray and photoluminescence analyses.

\section{Summary and Conclusion}

In summary, we have systematically studied the effect of precursor solution concentration on the materials quality, orientation, and optical property of the $\mathrm{ZnO}$ nanorods grown on flexible ITO/PET substrates. Our investigation demonstrates that the morphology, crystal orientation, and optical 
property of $\mathrm{ZnO}$ nanorods grown on ITO/PET substrates can be tailored by changing the concentration of the precursor solution. By tuning the precursor concentration, we can grow nanorods with different morphology, crystal quality, and orientation. X-ray diffraction and micro-Raman spectroscopy showed that the $\mathrm{ZnO}$ nanorods with the highest concentration of $50 \mathrm{mM}$ were highly aligned and have the highest level of surface coverage. It was also found that the diameter and the length of the nanorods increase upon increasing precursor solution concentration. To the best of our knowledge, this is the first systematic investigation of studying the effect of precursor solution concentration on quality of $\mathrm{ZnO}$ nanorods grown on ITO/PET substrates by low-temperature solution method. We strongly believe that our work will contribute to the realization of flexible organicinorganic hybrid solar cell based on $\mathrm{ZnO}$ nanorods and polymer.

\section{Acknowledgment}

This work was supported by Korea Institute of Industrial Technology (KITECH).

\section{References}

[1] A. Ohtomo, M. Kawasaki, Y. Sakurai et al., "Room temperature ultraviolet laser emission from $\mathrm{ZnO}$ nanocrystal thin films grown by laser MBE," Materials Science and Engineering $B$, vol. 54, no. 1-2, pp. 24-28, 1998.

[2] M. Godlewski, E. Guziewicz, K. Kopalko et al., "Zinc oxide for electronic, photovoltaic and optoelectronic applications," Low Temperature Physics, vol. 37, no. 3, Article ID 009103LTP, pp. 235-240, 2011.

[3] G. C. Yi, C. R. Wang, and W. I. Park, "ZnO nanorods: synthesis, characterization and applications," Semiconductor Science and Technology, vol. 20, no. 4, pp. S22-S34, 2005.

[4] K. Takanezawa, K. Hirota, Q. S. Wei, K. Tajima, and K. Hashimoto, "Efficient charge collection with $\mathrm{ZnO}$ nanorod array in hybrid photovoltaic devices," Journal of Physical Chemistry C, vol. 111, no. 19, pp. 7218-7223, 2007.

[5] P. Ravirajan, A. M. Peiró, M. K. Nazeeruddin et al., "Hybrid polymer/zinc oxide photovoltaic devices with vertically oriented $\mathrm{ZnO}$ nanorods and an amphiphilic molecular interface layer," Journal of Physical Chemistry B, vol. 110, no. 15, pp. 7635-7639, 2006.

[6] C. Y. Chou, J. S. Huang, C. H. Wu, C. Y. Lee, and C. F. Lin, "Lengthening the polymer solidification time to improve the performance of polymer/ZnO nanorod hybrid solar cells," Solar Energy Materials and Solar Cells, vol. 93, no. 9, pp. 16081612, 2009.

[7] D. C. Olson, J. Piris, R. T. Collins, S. E. Shaheen, and D. S. Ginley, "Hybrid photovoltaic devices of polymer and $\mathrm{ZnO}$ nanofiber composites," Thin Solid Films, vol. 496, no. 1, pp. 26-29, 2006.

[8] B. D. Yao, Y. F. Chan, and N. Wang, "Formation of ZnO nanostructures by a simple way of thermal evaporation," Applied Physics Letters, vol. 81, no. 4, pp. 757-759, 2002.

[9] Y. Dai, Y. Zhang, Q. K. Li, and C. W. Nan, "Synthesis and optical properties of tetrapod-like zinc oxide nanorods," Chemical Physics Letters, vol. 358, no. 1-2, pp. 83-86, 2002.
[10] A. J. Cheng, Y. Tzeng, Y. Zhou et al., "Thermal chemical vapor deposition growth of zinc oxide nanostructures for dye-sensitized solar cell fabrication," Applied Physics Letters, vol. 92, no. 9, Article ID 092113, 3 pages, 2008.

[11] W. I. Park, D. H. Kim, S. W. Jung, and G. C. Yi, "Metalorganic vapor-phase epitaxial growth of vertically well-aligned $\mathrm{ZnO}$ nanorods," Applied Physics Letters, vol. 80, no. 22, pp. 42324234, 2002.

[12] X. Liu, X. Wu, H. Cao, and R. P. H. Chang, "Growth mechanism and properties of $\mathrm{ZnO}$ nanorods synthesized by plasmaenhanced chemical vapor deposition," Journal of Applied Physics, vol. 95, no. 6, pp. 3141-3147, 2004.

[13] K. Ogata, K. Maejima, S. Z. Fujita, and S. G. Fujita, "Growth mode control of $\mathrm{ZnO}$ toward nanorod structures or highquality layered structures by metal-organic vapor phase epitaxy," Journal of Crystal Growth, vol. 248, pp. 25-30, 2003.

[14] Y. H. Ni, X. W. Wei, J. M. Hong, and Y. Ye, "Hydrothermal preparation and optical properties of $\mathrm{ZnO}$ nanorods," Materials Science and Engineering B, vol. 121, no. 1-2, pp. 42-47, 2005.

[15] L. Fan, H. Song, T. Li et al., "Hydrothermal synthesis and photoluminescent properties of $\mathrm{ZnO}$ nanorods," Journal of Luminescence, vol. 122-123, no. 1-2, pp. 819-821, 2007.

[16] D. Polsongkram, P. Chamninok, S. Pukird et al., "Effect of synthesis conditions on the growth of $\mathrm{ZnO}$ nanorods via hydrothermal method," Physica B, vol. 403, no. 19-20, pp. 37133717, 2008.

[17] H. Ahn, Y. Wang, S. H. Jee, M. Park, Y. S. Yoon, and D. J. Kim, "Enhanced UV activation of electrochemically doped $\mathrm{Ni}$ in $\mathrm{ZnO}$ nanorods for room temperature acetone sensing," Chemical Physics Letters, vol. 511, no. 4-6, pp. 331-335, 2011.

[18] M. Guo, P. Diao, and S. Cai, "Hydrothermal growth of wellaligned $\mathrm{ZnO}$ nanorod arrays: dependence of morphology and alignment ordering upon preparing conditions," Journal of Solid State Chemistry, vol. 178, no. 6, pp. 1864-1873, 2005.

[19] C. J. Brabec, N. S. Sariciftci, and J. C. Hummelen, "Plastic solar cells," Advanced Functional Materials, vol. 11, no. 1, pp. 15-26, 2001.

[20] J. J. Kim, K. S. Kim, and G. Y. Jung, "Fabrication of flexible dye-sensitised solar cells with photoanodes composed of periodically aligned single crystalline vertical $\mathrm{ZnO}$ NRs by utilising a direct metal transfer method," Journal of Materials Chemistry, vol. 21, no. 21, pp. 7730-7735, 2011.

[21] A. Hu, F. Wu, J. Liu et al., "Density- and adhesion-controlled $\mathrm{ZnO}$ nanorod arrays on the ITO flexible substrates and their electrochromic performance," Journal of Alloys and Compounds, vol. 507, no. 1, pp. 261-266, 2010.

[22] H. Ahn, J.-H. Park, S.-B. Kim, S. H. Jee, Y. S. Yoon, and D.J. Kim, "Vertically aligned $\mathrm{ZnO}$ nanorod sensor on flexible substrate for ethanol gas monitoring," Electrochemical and Solid-State Letters, vol. 13, no. 11, pp. J125-J128, 2010.

[23] N. Lepot, M. K. Van Bael, H. Van den Rul et al., "Synthesis of $\mathrm{ZnO}$ nanorods from aqueous solution," Materials Letters, vol. 61, no. 13, pp. 2624-2627, 2007.

[24] Joint Committee on Powder Diffraction Standards, "Mineral powder diffraction file: databook: sets 1-42," Powder Diffraction File no. 36-1451.

[25] B. Lo, J. Y. Chang, A. V. Ghule, S. H. Tzing, and Y. C. Ling, "Seed-mediated fabrication of $\mathrm{ZnO}$ nanorods with controllable morphology and photoluminescence properties," Scripta Materialia, vol. 54, no. 3, pp. 411-415, 2006.

[26] A. Umar, B. Karunagaran, E.-K. Suh, and Y. B. Hahn, "Structural and optical properties of single-crystalline $\mathrm{ZnO}$ 
nanorods grown on silicon by thermal evaporation," Nanotechnology, vol. 17, no. 16, pp. 4072-4077, 2006.

[27] S. S. Hong, T. Joo, W. I. Park, Y. H. Jun, and G. C. Yi, “Timeresolved photoluminescence of the size-controlled $\mathrm{ZnO}$ nanorods," Applied Physics Letters, vol. 83, no. 20, pp. 4157-4159, 2003.

[28] Y. Sun, J. B. Ketterson, and G. K. L. Wong, "Excitonic gain and stimulated ultraviolet emission in nanocrystalline zinc-oxide powder," Applied Physics Letters, vol. 77, no. 15, pp. 2322-2324, 2000.

[29] Z. L. Wang, "Zinc oxide nanostructures: growth, properties and applications," Journal of Physics, vol. 16, no. 25, pp. R829R858, 2004.

[30] H. J. Egelhaaf and D. Oelkrug, "Luminescence and nonradiative deactivation of excited states involving oxygen defect centers in polycrystalline ZnO," Journal of Crystal Growth, vol. 161, no. 1-4, pp. 190-194, 1996.

[31] J. M. Calleja and M. Cardona, "Resonant Raman scattering in ZnO," Physical Review B, vol. 16, no. 8, pp. 3753-3761, 1977.

[32] H. C. Hsu, H. M. Cheng, C. Y. Wu, H. S. Huang, Y. C. Lee, and W. F. Hsieh, "Luminescence of selective area growth of epitaxial $\mathrm{ZnO}$ nanowires and random-growth-oriented nanobelts," Nanotechnology, vol. 17, no. 5, pp. 1404-1407, 2006.

[33] R. Cuscó, E. Alarcón-Lladó, J. Ibáñez et al., "Temperature dependence of Raman scattering in ZnO," Physical Review B, vol. 75, no. 16, Article ID 165202, 11 pages, 2007.

[34] A. J. Cheng, Y. Tzeng, H. Xu et al., "Raman analysis of longitudinal optical phonon-plasmon coupled modes of aligned $\mathrm{ZnO}$ nanorods," Journal of Applied Physics, vol. 105, no. 7, Article ID 073104, 7 pages, 2009.

[35] E. Alarcón-Lladó, J. Ibáñez, R. Cuscó et al., "Ultraviolet Raman scattering in $\mathrm{ZnO}$ nanowires: quasimode mixing and temperature effects," Journal of Raman Spectroscopy, vol. 42, no. 2, pp. 153-159, 2011.

[36] Y. Tong, Y. Liu, C. Shao et al., "Growth and optical properties of faceted hexagonal $\mathrm{ZnO}$ nanotubes," Journal of Physical Chemistry B, vol. 110, no. 30, pp. 14714-14718, 2006. 

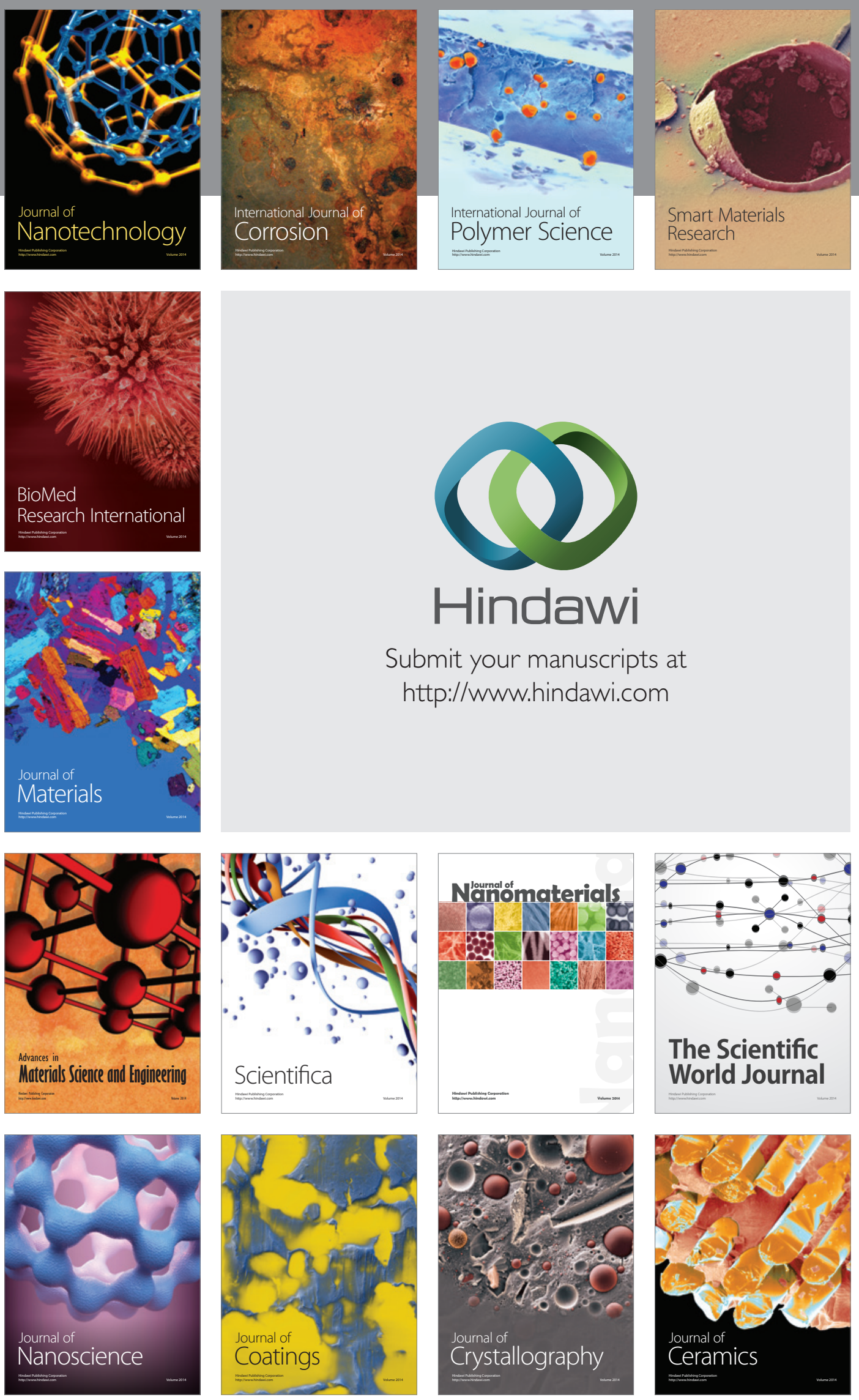

The Scientific World Journal

Submit your manuscripts at

http://www.hindawi.com

\section{World Journal}

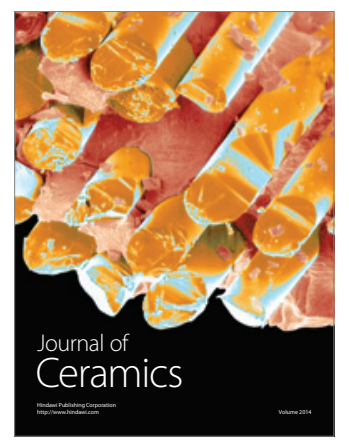

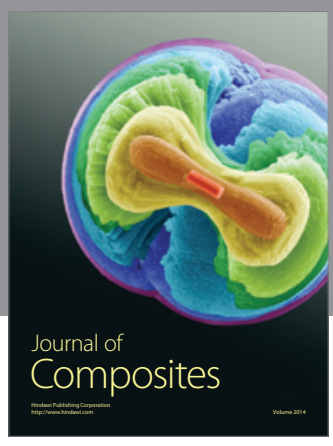
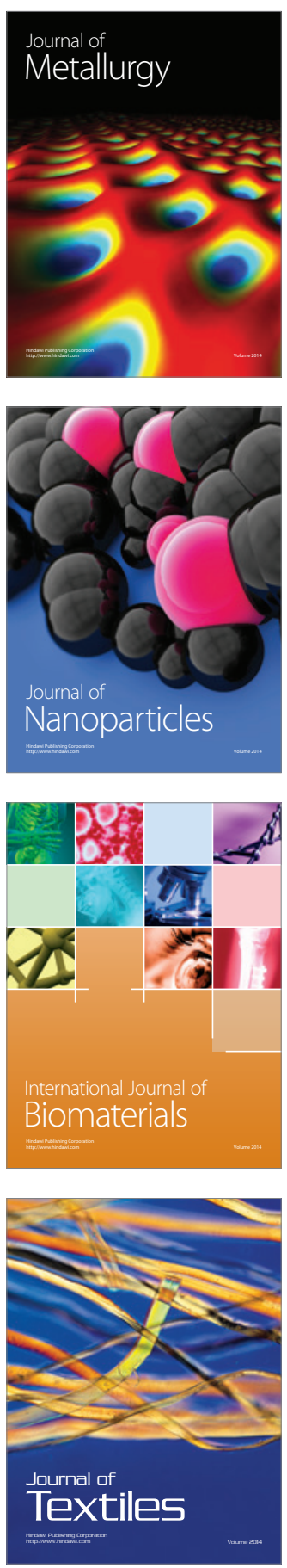